\title{
On Viable Service Systems: Developing a Modeling Framework for Analysis of Viability in Service Systems
}

\author{
Arash Golnam, Gil Regev and Alain Wegmann
}

Ecole Polytechnique Fédérale de Lausanne (EPFL)

School of Computer and Communication Sciences

CH-1015 Lausanne, Switzerland

\{arash.golnam, gil.regev, alain.wegmann\}@epfl.ch

\begin{abstract}
This paper explores the contribution of systems modeling to the design and analysis of viability in service systems. We apply a modeling framework called SEAM (Systemic Enterprise Architecture Method) to gain an understanding of how a service system maintains its identity and remains viable in its environment. SEAM embodies theoretical insights from systems science and organizational cybernetics, in particular the viable system model of Stafford Beer. We illustrate the applicability of the framework by modeling the design of viability in a service system.
\end{abstract}

Keywords: Viable Service Systems, Systems Science, SEAM, Viable System Model

\section{Introduction}

The concept of "service system" is central to service science (SS) and servicedominant (SD) logic [1-3]. A service system is defined as "a configuration of people, technologies, organization and shared information, able to create value to providers, users and other interested entities, through service" [4]. Recently, service science researchers have shown an increasing interest in studying viable service systems (VSS) and discovering the factors that contribute to the viability of a service system.

From a systems perspective, a system is viable only when it maintains some aspects that enable the observer to identify it as different from other systems. The observer, in effect, invents the system by perceiving a purposive unity [5]. In other words, a system is defined only when an observer detects and identifies a set of entities standing in interrelations. Hence, when a system loses the aspects that help the observer distinguish it from other systems, it passes out of existence.

As the study of viable systems is a disciplined inquiry in systems science, exploration of the contributions of systems science to the study of VSS has emerged 
as a topic of relatively high importance among the researchers in the field. A recent issue (Spring/Summer 2010) of the Journal of Service Science is dedicated to the insights and the inferences of systems science upon research in the realm of service and in particular VSS. Understanding the building blocks of systems science can lead to a better insight into the nature of the contributions that systems science can make to the study of VSS.

In [6], Banathy categorizes systems science into three domains of inquiry: systems theory, systems philosophy and systems methodology. Systems philosophy embodies the fundamental assumptions that provide the perspectives that give us insights into defining and categorizing the concepts and principles that are the building blocks of systems theory. Systems theory provides the theoretical insights that can be invoked to build an understanding of the complexities of some aspect of reality. Systems theory refers to the science of systems that resulted from Bertalanffy's General Systems Theory (GST). GST provides "models, principles and laws that can be generalized across various systems, their components and the relationship among them" [7]. GST is, in effect, a theory of universal principles that are common and apply to systems in general. Finally, systems methodology aims at the instrumentalization of systems theory and its application to a functional context [6]. It involves developing models and methods to make adequate predictions or retrodictions about some aspect of reality and to learn how to control a phenomenon of interest in a desirable way [8]".

A large and a growing body of literature in service science invokes theoretical insights from systems theory in particular GST and Cybernetics in order to examine various aspects of viability and gain an understanding of the factors that can contribute to the viability of a service system. (For instance see [9-10]).

Our research, however, involves a systems methodological approach to assist the design and analysis of the viability of a service system. Systems methodology provides a means for developing concrete applications and instantiations of the theoretical insights from systems science. In other words, systems methodology serves to connect the theoretical aspects of viability of a service system to an actual viable service system functioning in its context. It thereby sheds light on the preconditions necessary for a service system to meet the criterion of viability. This is achieved by means of applying models and methods that embody systems theory.

In this paper, we apply the Systemic Enterprise Architecture Method (SEAM) to represent and analyze a service system through the lens of viability. SEAM embodies theoretical insights from GST and the viable system model (VSM) developed by Stafford Beer [11-12]. SEAM is designed to analyze and assist in the design of business and engineering strategies. Developed at Ecole Polytechnique Fédérale de Lausanne (EPFL), SEAM has been used for teaching [13] and consulting [14] since 2001.

We illustrate the application of the modeling framework with an example inspired by a consulting project we undertook for a Swiss utility company called SIG (Services Industriels de Genève). The project we conducted at this utility company helped us gain important insights into various aspects of its service offering and implementation and thus makes the example concrete.

Our discussion is structured in the following way. In Section 2, we explain the key conceptualizations and the related theoretical principles that we employ in our 
modeling process. These conceptualizations are graphically represented in a "conceptual model". In Section 3, we model the utility company as a service system by applying the SEAM modeling framework. The theoretical insights embodied in our conceptualizations and thereby in our SEAM model will contribute to our understanding of the mechanisms by means of which the utility company maintains its viability. In Section 4, we discuss the related work and we present our conclusion and future work in Section 5. Throughout the paper we define a number of important terms from systems science that can contribute to a shared understanding of key systems terminologies and concepts used in this paper.

\section{Conceptualizations}

Central to systems methodology, is the practice of systems modeling. In systems modeling we construct systems that are adequate models of some aspects of reality [8]. The first step of systems modeling process is for the modeler to observe some aspect of reality referred to as the "universe of discourse" (UoD). Employing a set of conceptualizations, the modeler then tries to distinguish a set of entities that compose the universe of discourse and the relationships between them. In effect, the conceptualizations employed in a model form a lens through which the modeler observes phenomena of interest in a UoD. [15]. For instance, when a modeler looks at people who work in a building with a logo on the building, the modeler's conceptualization of what is a "company" - if it matches what she sees - will help her realize that she is looking at a company. Without such conceptualization, the modeler would never be able to recognize the company.

Next, the modeler develops a model in the representation domain. The model is composed of modeling constructs that represent the observed entities in the UoD. The conceptualization explains the kinds of modeling constructs in the representation domain and allows a mapping between the modeling constructs in the representation domain and the entities observed in the universe of discourse. A conceptualization thereby gives the modeling constructs a real-world interpretation. Figure 1 represents the process of systems modeling.

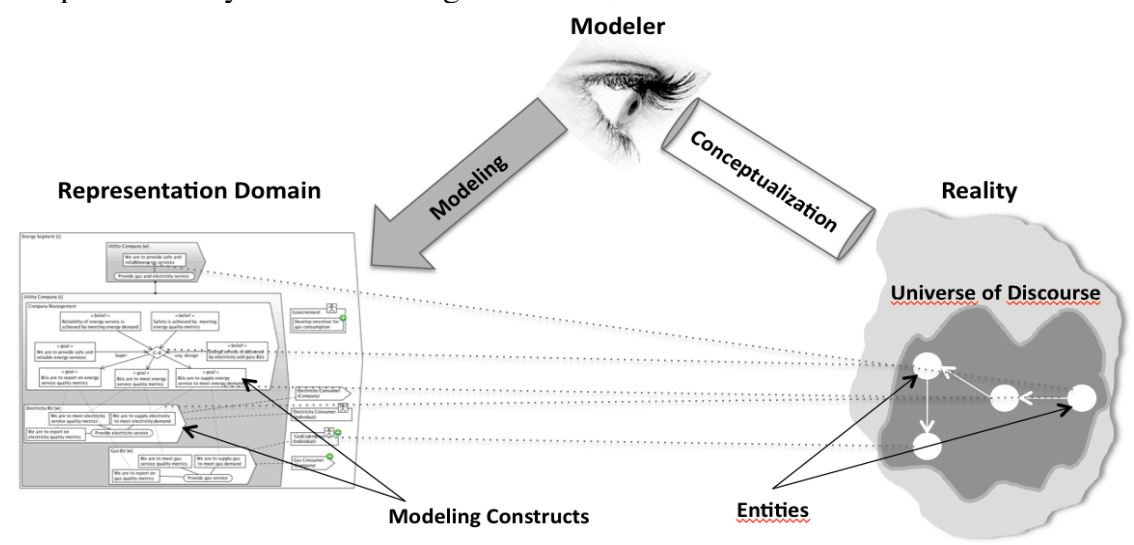

Fig. 1. The modeling process 
In this paper we follow the modeling process illustrated in Figure1. SIG constitutes our universe of discourse and SEAM is the modeling framework we apply to build models of SIG in the representation domain. Our conceptualizations are based upon GST and Cybernetics, in particular the work of Stafford Beer. Based on this understanding, we conceptualize the observed system in the UoD as a set of interacting systems and the channels that connect these to each other and to their environment.

Figure 2 is a graphical representation of the conceptualizations employed in our model building process. We call this graphical representation a "conceptual model". In the following sections we explain and interpret various parts, as well as the diagrammatic conventions of the conceptual model.

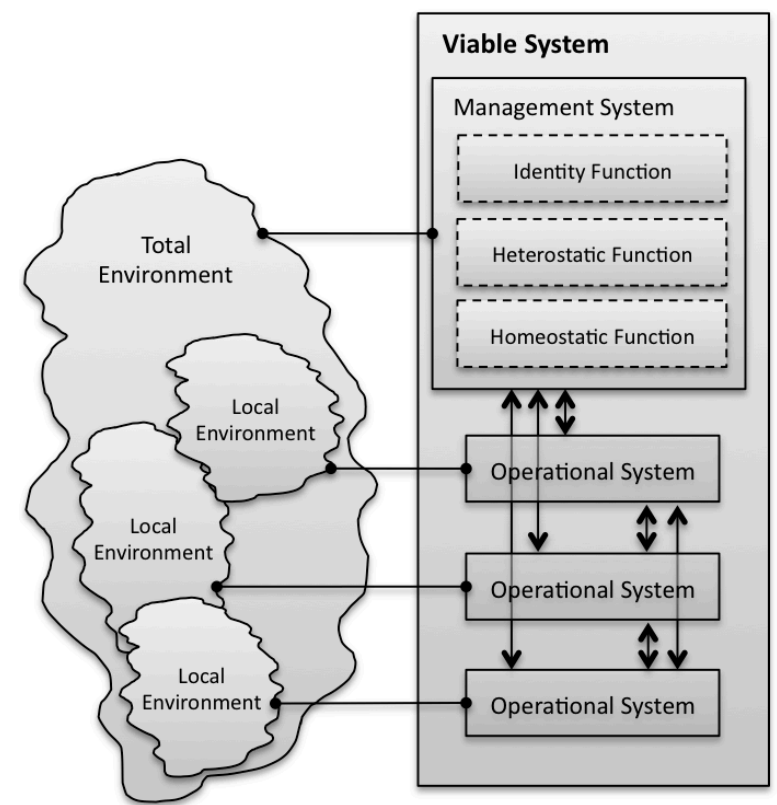

Fig. 2. The conceptual Model of a Viable System

\subsection{Systems}

Our conceptualizations are inspired by the work of Stafford Beer and in particular the viable system model (VSM) [11-12]. We decompose a viable system into a set of operational systems that interact with a management system.

Operational Systems. Operational systems are the systems that perform the operations within a viable system. Operations create the outputs that justify the existence of the system from the observer's point-of-view. Hence, the functions of the operational systems are the reason that the system exists in the first place [12]. Recursively, an operational system is in turn a viable system. This means, an 
operational system contains smaller operational systems and is contained in a hierarchy of larger operational systems. Thus, an operational system can be decomposed to its constituent operational systems and its management system. In Figure 2, we illustrate a viable system with three operational systems. The operational systems in our conceptual model correspond to System 1 in VSM.

Management System. The management system performs a set of systemic functions necessary for the system to remain viable. In the following we discuss the main functions of the management system.

Homeostasic Function. The homeostatic function of the management system directs the "inside and now" operations (i.e. the current and internal operations). It develops a black-box view of the operational systems (i.e. viewing only their inputs and outputs without knowing their internal functions and constituent systems) and looks for ways to optimize the overall efficiency and improve the performance of the operational systems by overviewing their interactions. It also regulates the operational systems to keep the overall operations running smoothly, and to deal with and recover from any disruptions and oscillations. In order to achieve regulation, it communicates the desired bounds of certain variables of the operational systems and monitors compliance. Regulation of the interrelated operational systems creates synergy and makes the system more than the sum of its parts. Stability is an emergent property of the homeostatic function of the management system. The homeostatic function of the management system in our conceptualization maps onto System 2, 3 and $3 *$ in VSM.

Heterostatic Function. The heterostasic function deals with "outside and future". It guarantees the adaptation of the system as a whole to a changing environment. In so doing, the heterostatic function requires an understanding of the total environment in which the system is embedded; which is beyond the capability of the operational systems, as they concern themselves with their local environment, which is only a sub-set of this total environment. As well as interacting with the environment, the heterostasic function needs to interact with the homeostatic function. This is because adaptation cannot be achieved without an understanding of the system as it currently exists. Evolution and adaptation are the emergent properties of the heterostatic function of the management system [16]. In Beer's VSM, System 4 performs the heterostatic function.

Identity Function. The identity function maintains the identity and ethos of the system by balancing the "inside and now" (i.e. homeostatic) and the "outside and future" (i.e. hetereostatic) functions. Identity is defined as the set of variables by means of which an observer identifies and distinguishes the system from other systems. Identity can be interpreted as invariance in some certain aspects of the system, in spite of all the changes that the system is going through [Weinberg]. Hence, a system can sustain its identity only when a proper balance between stability and change is made. The identity function is performed by System 5 in VSM. 


\subsection{Channels}

A system collapses if it does not interact with its environment. Thus, openness to environment is a precondition to viability. A system should interact and communicate with its environment in order to maintain its viability [17]. Channels enable the interaction and communication between the entities within the system and the entities with the environment. Two sets of channels can be distinguished in the conceptual model.

The inter-connecting channels within the system that are represented by arrows in Figure 2. These channels enable operational systems' interactions and, communication between the operational systems and the management system.

The channels connecting the system elements to the environment that are denoted by round tip lines in the conceptual model. These channels enable the operational systems' interactions with their local environments as well as the interaction between the management system and the total environment of the system.

\subsection{Viability}

The viability of a system is a function of the balance between homeostasis (i.e. stability) versus heterostasis (i.e. adaptability) [12]. A system achieves viability by maintaining the aspects of its operations that are linked to its identity (i.e. the aspects that enable the observer to identify the system). Maintenance of these aspects requires the management system to keep the state of some variables of the operational systems stable and/or precipitate change in the state of some operational systems' variables. Recursively, the states that an operational system is to maintain or achieve constitute its identity from the point of view of the management system. Hence, the management system within each operational system is to ensure the achievement or maintenance of those states, for the operational system to remain viable.

\section{Modeling and Analysis of Viability in a Service System}

In this section we develop SEAM models of SIG based on the conceptualizations explained in section 2. In the SEAM models, SIG is referred to as "Utility Company". Figure 3 is a SEAM model of the Utility Company in the Energy Segment.

In SEAM a system is denoted by a block arrow and can be represented as a whole (i.e. black box) or as a composite (i.e. white box). Modeling the Energy Segment as a composite we represent the Utility Company as the service system and its total environment. The environment of the service system comprises the Government as the regulator and Gas and Electricity Consumers (Individual and Company) as the service adopters. 


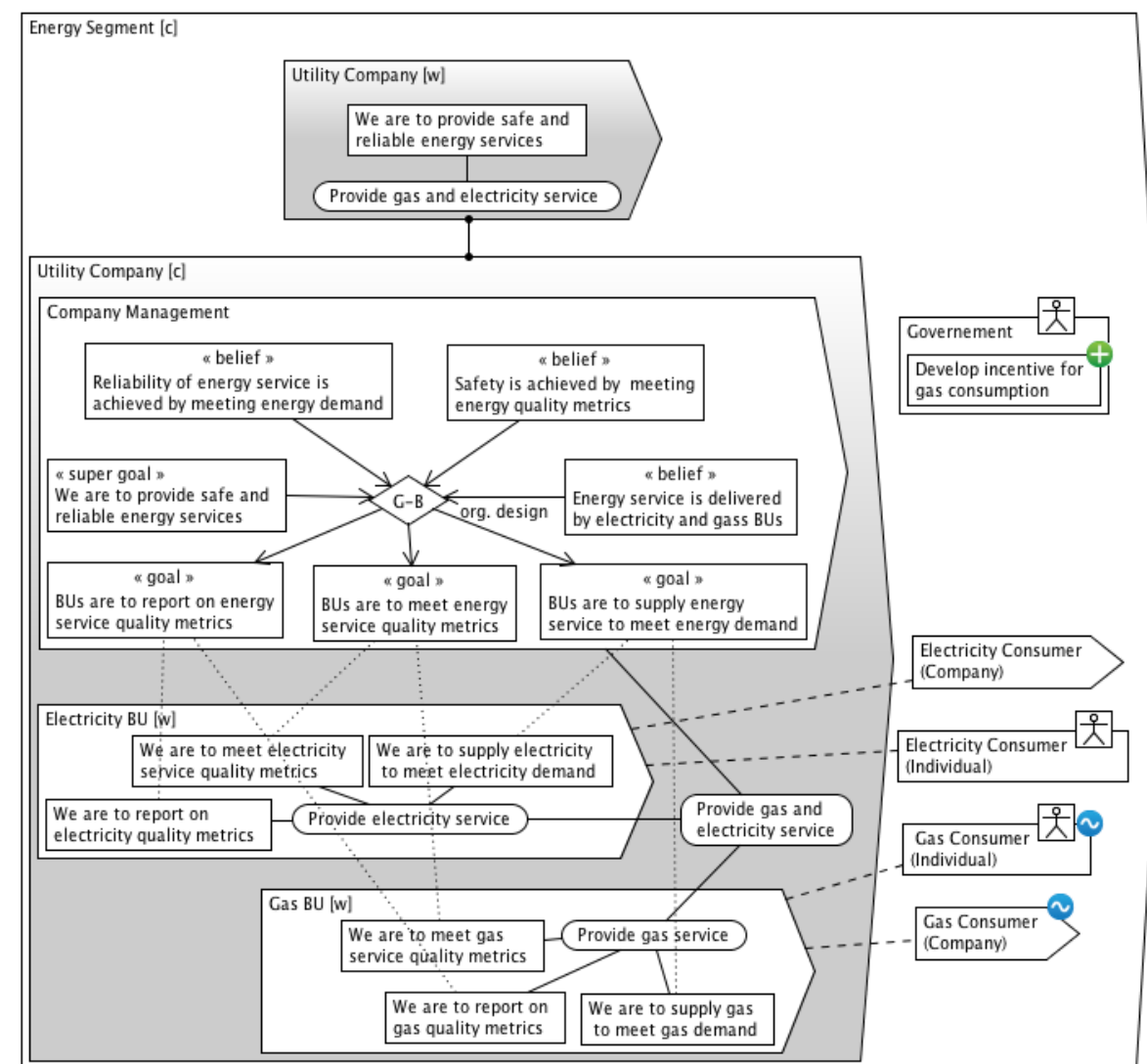

Fig. 3. Utility Company in Gas Segment

We conceptualize a service system as an operational system. Thereby, the service systems in our SEAM models correspond to the operational systems in the conceptual model. Therefore, considering the recursive nature of the operational systems, is composed of its constituent service systems and a management system.

A service system is characterized by its behavior and properties. In SEAM, behaviors and properties are represented by ovals and rectangles. Service systems as wholes and as composites have behaviors and properties.

We call the behavior of a service system as a whole "service". The behavior of a service system as a composite is called "process". This process captures the implementation of the service. Representing a service system as a composite we model how its service systems and management system contribute to the service implementation process.

In Figure 3, "Provide gas and electricity service" is the service, the Utility Company as a whole, is offering to the adopters. Modeling the Utility Company as a composite, we represent the Company Management (i.e. the management system) and Electricity BU and Gas BU (i.e. service systems) and their contribution to "Provide gas and electricity service". 
The property of a service system as a whole captures the "identity" of the service system. The identity of a service system is expressed by a prescriptive statement that conveys what the service system is to do in order to sustain its viability.

We model the way a service system sustains its identity by considering maintenance of a particular identity property as a super goal and refining it to a set of $(s u b)$ goals. This refinement is a cognitive process carried out by the management system with the help of the beliefs it holds. Beliefs, in effect, represent the management system's interpretations of the state of service system and the systems with which the service system interacts.

Based on the explanations in Section 2.3, goals are grouped into two categories. The first category includes the goals that represent the changes that are to be made to some states of the service system. We refer to these goals as achievement goals. Goals in the second category specify the states of the service system that are to be kept the same and maintained. We call these goals maintenance goals. Achievement and maintenance goals respectively reflect the heterostatic and the homeostatic functions of the management system within a service system.

The management system of the service system then, assigns goals to the constituent service systems. These goals are to be considered by the service systems as the super goals and are thereby refined to a set of achievement and/or maintenance goals.

In Figure 3, "We are to provide safe and reliable energy services" is the identity property of the Utility Company as a whole, which is then perceived by the Company Management as a super goal. The Company Management believes that "Reliability of energy service is achieved by meeting energy demand" and the belief that "Energy service is delivered by electricity and gas BUs" is derived from the organization design of the Utility Company (in the SEAM models, such goals are annotated by "org. design"). Based on these beliefs, the goal "BUs are to supply energy service to meet energy demand" is developed by the Company Management as a refinement of the super goal. This goal is then communicated to the BUs by the management system as their identity properties. The Gas BU interprets this goal as "We are to supply gas service to meet gas demand". Other parts of the model can be interpreted the same way.

The pluses in the Figure 3 mark the emergence of new entities in the universe of discourse. As it can be seen the government develops incentives for gas consumption. The new incentives lead to an increase in the number of the Gas Consumers (private and company).

In Figure 4, we represent the Gas BU as a composite. The composite view of the Gas BU, provides us with insights into the beliefs and the goals the Gas BU Management holds. The increase in the number of gas consumers leads to the belief "Demand for gas is rising". The Gas BU management also believes that "Gas supply is adjusted by increasing or decreasing the pressure in pipes" and the organization design of the Gas BU derives the belief that "Gas supply dept. adjusts the pressure in pipes". As the identity of the Gas BU is geared to meeting the demand, the BU management formulates the achievement goal "Gas supply dept. is to increase the pressure in pipes". 


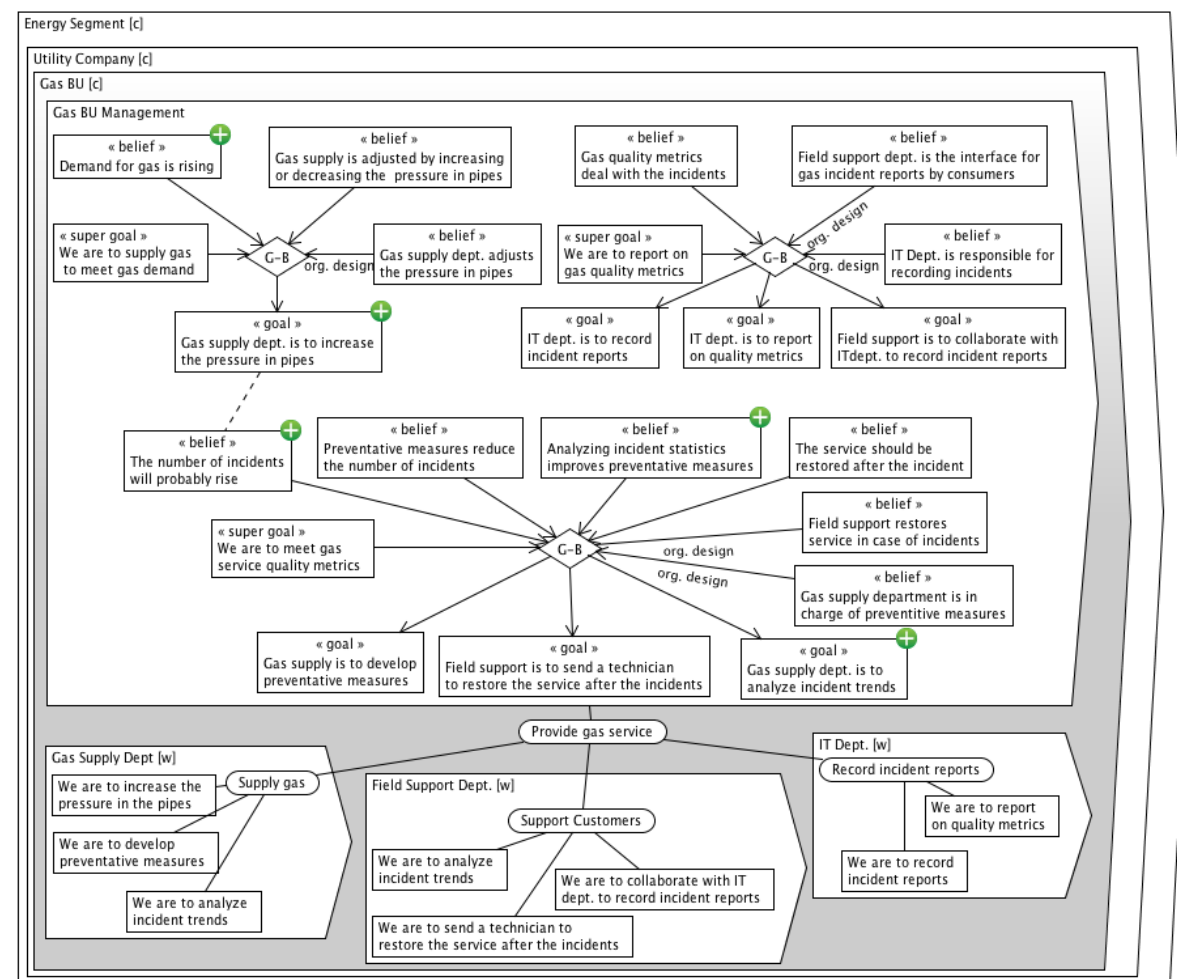

Fig. 4. Gas BU in the Utility Company

The Gas BU, on the other hand, is to report on and meet the gas service quality service in order to sustain its identity. As illustrated in Figure 4, the Gas BU believes that "Gas quality metrics deal with incidents" and "preventative measures reduce the number of incidents". Increasing the pressure in pipes gives rise to the belief "The number of incidents will probably rise". The rise in the number of incidents leads to the inability of the Gas BU to meet the super goal "We are to meet the gas service quality metrics" and consequently puts the viability of the Gas BU and the Utility Company in threat.

The belief " Analyzing incident statistics improves preventative measures" reflects how the Gas BU management plans to counteract the effect of the increase in the pressure in pipes. Analysis of incident statistics results in the development of more effective preventative measures and therefore decreases the incidents. As "Gas supply dept. is in charge of preventative measures", a belief stemming from the organization design, the Gas BU Management formulates the maintenance goal "Gas supply dept. is to analyze incident trends".

Representing the Gas BU as a composite we also model the contribution of its departments to the implementation of the "Provide gas energy" service.

In Table 1, we present a mapping between the conceptualizations, SEAM modeling constructs and the entities in the universe of discourse in the modeling process of this paper. 
Table 1. Mapping between the conceptualizations, modeling constructs and entities in the UoD.

\begin{tabular}{|c|c|c|c|}
\hline & \multicolumn{2}{|c|}{ Entities in the UoD } \\
\hline Conceptualizations & Modeling constructs & Utility Company [c] & Gas BU [c] \\
\hline Management system & $\begin{array}{ll}\text { Service } & \text { system } \\
\text { management } & \\
\end{array}$ & Company Management & BU Management \\
\hline Operational system & Service system & Electricity BU, Gas BU & $\begin{array}{l}\text { IT Dept., Field Support Dept., Gas } \\
\text { Supply Dept. }\end{array}$ \\
\hline Identity & Super goal & $\begin{array}{l}\text { We are to provide safe and } \\
\text { reliable services }\end{array}$ & $\begin{array}{l}\text { We are to supply gas service to } \\
\text { meet gas demand }\end{array}$ \\
\hline $\begin{array}{l}\text { Homeostatic } \\
\text { function }\end{array}$ & Maintenance goal & $\begin{array}{l}\text { - } \begin{array}{l}\text { BUs are to supply energy } \\
\text { service to meet energy } \\
\text { demand }\end{array} \\
\ldots\end{array}$ & $\begin{array}{l}\text { - IT dept. is to report on quality } \\
\text { metrics } \\
\text { - Gas supply is to analyze incident } \\
\text { trends }\end{array}$ \\
\hline Heterostatic function & Achievement goal & --- & $\begin{array}{l}\text { - Gas supply dept. is to increase } \\
\text { the pressure in pipes }\end{array}$ \\
\hline
\end{tabular}

\section{Related Work}

We divide our related work into two categories of research activities: research aimed at gaining insights into viability in service systems by applying theoretical frameworks from systems science and the viable system model and, the attempts made in developing conceptual modeling techniques that can contribute to service management.

In the first stream of research, in [18], the authors compare the fundamental concepts of smart service systems and viable service systems, highlighting the potential mappings between the service science and systems science principles. In [19], the author explains the implications of the law of requisite variety within the service science and reasons about the mechanisms through which a system deals with the variety introduced by its environment. [20] provides an application of VSM to tourism services.

In the realm of conceptual modeling; e3Service [21] is a method for semiautomatically reasoning about matching service offerings with customer needs. In order to make this semi automatic reasoning possible, e3Service assumes that the customer and supplier share the same ontology, that the customer specifies her needs in the same vocabulary as the supplier specifies its offering. In SEAM, we precisely avoid to make this simplifying assumption. This comes at the cost of enormously complicating automatic or event semi-automatic reasoning with the benefit of models that more accurately reflect reality.

$\mathrm{i}^{*}[22]$ is one of the leading modeling method used in the requirements engineering research community for reasoning about FR and NFR. $i^{*}$ provides modeling artifacts for reasoning about alternative satisfactions of NFR. $i^{*}$ models describe relationships as actors dependencies. Hence, $i^{*}$ offers support for reasoning about alternatives. $i^{*}$ has been extended with value reasoning in [23] . 


\section{Conclusion and Future Work}

This paper was an attempt to apply the viability theory developed in systems science and cybernetics to the service science. To do so, we applied a modeling technique called SEAM. The modeling constructs in the SEAM models enable us to map the theoretical conceptualizations of viability onto the mechanisms through with a service system remains viable. Our approach was illustrated by modeling and analysis of viability in a service system.

Our future work focuses on augmenting the modeling framework with variety concepts and applying it to a prospective case in order to develop prescriptions on a viability compatible design.

\section{References}

1. S. L. Vargo and R. F. Lusch, "Evolving to a new dominant logic for marketing," Journal of marketing, vol. 68 , no. 1, pp. 1-17, 2004.

2. R. F. Lusch and S. L. Vargo, The service-dominant logic of marketing: dialog, debate, and directions. ME Sharpe Inc, 2006.

3. S. L. Vargo and R. F. Lusch, "Service-dominant logic: continuing the evolution," Journal of the Academy of Marketing Science, vol. 36, no. 1, pp. 1-10, 2008.

4. P. P. Maglio and J. Spohrer, "Fundamentals of service science," Journal of the Academy of Marketing Science, vol. 36, no. 1, pp. 18-20, 2008.

5. G. M. Weinberg, An introduction to general systems thinking (silver anniversary ed.). Dorset House Publishing Co., Inc. New York, NY, USA, 2001.

6. B. H. Banathy and P. M. Jenlink, "Systems inquiry and its application in education," Handbook of Research on Educational Communications and Technology, 2nd ed. Mahwah, NJ: Lawrence Erlbaum Associates, Inc, 2004.

7. L. V. Bertalanffy, General System Theory: Foundations, Development, Applications, Revised. George Braziller, 1976.

8. G. J. Klir, Facets of Systems Science, 2nd ed. Springer, 2001.

9. S. Barile, J. Spohrer, and F. Polese, "System Thinking for Service Research Advances."

10. M. Saviano, C. Bassano, and M. Calabrese, "A VSA-SS Approach to Healthcare Service Systems The Triple Target of Efficiency, Effectiveness and Sustainability."

11. S. Beer, "The viable system model: its provenance, development, methodology and pathology," Journal of the Operational Research Society, vol. 35, no. 1, pp. 7-25, 1984.

12. S. Beer, The Heart of Enterprise. Wiley, 1995.

13. A. Wegmann, G. Regev, J. D. de la Cruz, L. S. Lê, and I. Rychkova, "Teaching Enterprise Architecture And Service-oriented Architecture in Practice," in Workshop on Trends in Enterprise Architecture Research (TEAR 2007), p. 13, 2007.

14. A. Wegmann, G. Regev, and B. Loison, "Business and IT Alignment with SEAM," 2005.

15. A. Tarski and J. Corcoran, Logic, semantics, metamathematics: papers from 1923 to 1938. Hackett publishing company, 1983.

16. W. F. Christopher, Holistic management: managing what matters for company success. Wiley-Interscience, 2007.

17. W. R. Ashby, An introduction to cybernetics. Chapman \& Hall London, 1956.

18 S. Barile and F. Polese, "Smart Service Systems and Viable Service Systems: Applying Systems Theory to Service Science," Journal of Service Science, vol. 2, no. 1, pp. 20- 
39,2010

19. P. Godsiff, "Service Systems and Requisite Variety," in The 2009 Naples Forum on Service: Service-Dominant Logic, Service Science and Network Theory, pp. 978-88.

20. R. L. Flood and S. A. Zambuni, "Viable systems diagnosis. 1. Application with a major tourism services group," Systemic Practice and Action Research, vol. 3, no. 3, pp. 225248, 1990.

21. S. de Kinderen and J. Gordijn, "E 3 Service: A Model-Based Approach for Generating Needs-Driven E-Service Bundles in a Networked Enterprise."

22. E. S. Yu, "Towards modelling and reasoning support for early-phase requirements engineering," in Requirements Engineering, 1997., Proceedings of the Third IEEE International Symposium on, pp. 226-235, 2002.

23. J. Gordijn, E. Yu, and B. van der Raadt, "e-Service Design Using i* and e3value Modeling," IEEE software, pp. 26-33, 2006. 